\title{
Stress perception following childhood adversity: Unique associations with adversity type and sex
}

\author{
Allison M. LoPilato ${ }^{1}$, Jean Addington², Carrie E. Bearden ${ }^{3}$, Kristin S. Cadenhead ${ }^{4}$, Tyrone D. Cannon ${ }^{5,6}$, \\ Barbara A. Cornblatt ${ }^{7}$, Daniel H. Mathalon ${ }^{8,9}$, Thomas H. McGlashann ${ }^{5}$, Diana O. Perkins ${ }^{10}$, Ming T. Tsuang ${ }^{4}$, \\ Scott W. Woods ${ }^{5}$ and Elaine F. Walker ${ }^{1,11}$ \\ ${ }^{1}$ Department of Psychiatry and Behavioral Sciences, Emory School of Medicine, Atlanta, Georgia, USA; ${ }^{2}$ Department of Psychiatry, University of Calgary, Calgary, \\ Canada; ${ }^{3}$ Semel Institute for Neuroscience and Human Behavior \& Department of Psychology, University of California, Los Angeles, Los Angeles, California, USA; \\ ${ }^{4}$ Department of Psychiatry, University of California, San Diego, San Diego, California USA; ${ }^{5}$ Department of Psychiatry, Yale University, New Haven, Connecticut, \\ USA; ${ }^{6}$ Department of Psychology, Yale University, New Haven, Connecticut, USA; ${ }^{7}$ Department of Psychiatry, Zucker Hillside Hospital, Queens, New York, USA; \\ ${ }^{8}$ Department of Psychiatry, University of California, San Francisco, San Francisco, California, USA; ${ }^{9}$ San Francisco VA Medical Center, San Francisco, California, USA; \\ ${ }^{10}$ Department of Psychiatry, University of North Carolina, Chapel Hill, North Carolina, USA and ${ }^{11}$ Department of Psychology, Emory University, Atlanta, Georgia, USA
}

\begin{abstract}
Childhood adversity is associated with poor mental and physical health outcomes across the life span. Alterations in the hypothalamicpituitary-adrenal axis are considered a key mechanism underlying these associations, although findings have been mixed. These inconsistencies suggest that other aspects of stress processing may underlie variations in this these associations, and that differences in adversity type, sex, and age may be relevant. The current study investigated the relationship between childhood adversity, stress perception, and morning cortisol, and examined whether differences in adversity type (generalized vs. threat and deprivation), sex, and age had distinct effects on these associations. Salivary cortisol samples, daily hassle stress ratings, and retrospective measures of childhood adversity were collected from a large sample of youth at risk for serious mental illness including psychoses $(n=605$, mean age $=19.3)$. Results indicated that childhood adversity was associated with increased stress perception, which subsequently predicted higher morning cortisol levels; however, these associations were specific to threat exposures in females. These findings highlight the role of stress perception in stress vulnerability following childhood adversity and highlight potential sex differences in the impact of threat exposures.
\end{abstract}

Keywords: childhood adversity, cortisol, deprivation, stress perception, threat

Childhood adversity is among the strongest predictors of psychopathology and is associated with a range of mood and psychotic symptoms that cut across diagnostic boundaries (Collinshaw et al., 2007; Danese et al., 2009; Evans, Li, \& Whipple, 2013; Kessler et al., 2010; Price, Kao, Burgers, Carpenter, \& Tyrka, 2013). In addition to conferring increased risk for serious mental illnesses such as schizophrenia and bipolar disorder (Mandelli, Perelli, \& Seretti, 2015; Palmier-Claus et al., 2016), exposure to childhood trauma is associated with subthreshold psychotic experiences (e.g., low-grade delusions, isolated auditory hallucinations, and perceptual aberrations), even among individuals who do not have a psychotic disorder (Kelleher et al., 2008). While there is general agreement around the broad principle that childhood adversity confers risk for psychopathology by altering developing stress systems, the cortisol findings have been inconsistent (Gunnar \& Quevedo, 2007b; Hunter, Minnis, \& Wilson, 2011;

Author for Correspondence: Allison M. LoPilato, Emory School of Medicine, Department of Psychiatry \& Behavioral Sciences, 12 Executive Park, Atlanta, GA 30329; E-mail: allison.lopilato@emory.edu.

Cite this article: LoPilato AM et al (2020). Stress perception following childhood adversity: Unique associations with adversity type and sex. Development and Psychopathology 32, 343-356. https://doi.org/10.1017/S0954579419000130
Lupien, McEwen, Gunnar, \& Heim, 2009; Repetti, Robles, \& Reynolds, 2011; Tyrka et al., 2008). These mixed findings raise the possibility that psychological aspects of stress processing, such as stress perception, may underlie variations in these associations, and that differences in adversity type, sex, and age may be relevant in understanding the diverse effects of childhood adversity on stress processes.

Previous research on childhood adversity has typically focused on the biological stress response and paid less attention to the subjective stress appraisals. However, transactional models of stress posit a dynamic interplay between stressful experiences, subjective stress perception, and neuroendocrine responses (Gunnar \& Quevedo, 2007a). These intermediary appraisal processes have been hypothesized to play a critical role in stress vulnerability (Olff, Langeland, \& Gersons, 2005). There is growing support and theorizing that early experiences shape an individual's perception of, and tolerance to, subsequent stressors later in life (Chen \& Baram, 2016; Hammen, Henry, \& Daley, 2000; Harkness, Hayden, \& Lopez-Duran, 2015; Maniam, Antoniadis, \& Morris, 2014; Pechtel, \& Pizzagalli, 2011). Active calibration and biological sensitivity to context models posit that information from early environments is used to calibrate activation thresholds and responses within stress systems to best match those 
environments (Boyce \& Ellis, 2005; Del Giudice, Ellis, \& Shirtcliff, 2011). Extending these theories to include stress perception raises the possibility that the psychological perception of stress may also be shaped to match the demands of childhood adversity. Early experiences and environments characterized by high levels of stress, unpredictability, low controllability, and unresponsive caregiving have been shown to have enduring effects on indices known to impact stress perception, including perceptions of control, cognitive biases, coping strategies, self-efficacy, and attributional styles (Chorpita \& Barlow, 1998; Jerusalem \& Schwarzer, 1992; Mittal \& Griskevicius, 2014; Repetti, Taylor, \& Seeman, 2002, Suzuki, Poon, Papadopoulos, Kumari, \& Cleare, 2014). Thus, childhood adversity may have specific effects on the development of an individual's subjective perceptions of stress.

Stress perception depends upon an individual's detection and appraisal of a threat within the context of the available coping resources (Folkman, Lazarus, Dunkel-Schetter, DeLongis, \& Gruen, 1986; Gunnar \& Vazquez, 2006; Lazarus \& Folkman, 1984). Both animal and human studies have found that experiences with controllable stressors in childhood facilitate the development of adaptive stress responding and detection thresholds via calibration of corticolimbic circuits (Maier, Amat, Baratta, Paul, \& Watkins, 2006; Mittal \& Griskevicius, 2014; Wadsworth, 2015). In childhood environments characterized by uncontrollable stressors, this calibration process is altered, such that the individual becomes more attuned and responsive to detecting potential stressors and threats (Chen \& Baram, 2016). While heightened detection promotes safety in adverse environments, it also has the potential to contribute to a dysfunctional state of hypervigilance in normal contexts. Another critical component of stress perception involves the individual's evaluation of his or her coping capacities (Lazarus \& Folkman, 1984; Lengua \& Long, 2002). Decreases in perceived coping resources have been found to increase subjective experiences of stress (Folkman et al. 1986). Childhood environments play a critical role in shaping the development of coping repertoires, which sets the stage for how stressors are evaluated later in life. While coping strategies are more flexible and context specific in childhood, they become increasingly traitlike in adulthood (Compas, Connor, Saltzman, Thomsen, \& Wadsworth, 1999).

Uncontrollable or unpredictable environments impede the development of active coping strategies, such as problem solving, which are less likely to be effective in these environmental contexts (Wadsworth, 2015). Instead, children who experience trauma often develop problematic coping strategies in an effort to protect themselves from harm and overwhelming stress (Ullman \& Peter-Hagene, 2014). While these strategies may be adaptive in their immediate environments, they impair an individual's ability to navigate future stressors (van Harmelen et al., 2010; Wadsworth, 2015). The combination of heightened threat detection and limited coping repertories, which may be viewed as functional adaptations to childhood adversity, are likely to have longstanding effects on an individual's propensity to appraise and react to the daily stressors later in life (Suzuki et al., 2014). Consistent with this proposed developmental sequelae, a large longitudinal study $(n=34,653)$ found that exposure to childhood adversity was related to a higher perceived intensity of daily stress in adults (McLaughlin, Conron, Koenen, \& Gilman, 2010). Similarly, a recent epidemiological community study found that childhood trauma was associated with higher subjective stress appraisals (Rössler, Ajdacic-Gross, Rodgers, Haker, \& Muller, 2016). Studies with depressed (Wichers et al., 2009) and psychosis risk (Lardinois, Lataster, Mengelers, van Os, \& Myin-Germeys, 2011) samples have also found that individuals exposed to childhood physical and sexual abuse show heightened stress perception toward minor daily hassles. These findings suggest that childhood adversities may have an enduring effect on the stress system via heightened perception of day-to-day stressors across the life span (Glaser, van Os, Portegijs, \& Myin-Germeys 2006).

Consistent with transactional models of stress, there is also evidence that stress perception modulates endocrine responses. Several studies have found associations between subjective perceptions of stress (e.g., magnitude, controllability, and coping ability) and biological stress response indices (Dickerson \& Kemeny, 2004; Juster, Perna, Marin, Sindi, \& Lupien, 2012; Sladek, Doane, Luecken, \& Eisenberg, 2016; Slattery, Grieve, Ames, Armstrong, \& Essex, 2013; Wirtz et al., 2007), although others have not (Schlotz et al., 2008). Specifically, some studies have found that cognitive appraisal of stressors accounts for approximately $20 \%-30 \%$ of the variance in cortisol response (Gaab et al., 2003; Gaab, Rohleder, Nater, \& Ehlert, 2005; Hammerfald et al., 2006). A recent study with healthy youth (ages 6-17) found that perceived stress had greater associations with basal cortisol and peak cortisol following a stressor task than objective experiences of stress (i.e., significant life events scale), even after controlling for anxiety (Allwood, Gaffey, Vergara-Lopez, \& Stroud, 2017). Meanwhile, a study with adolescents found that perceptions of coping abilities predicted acute cortisol reactivity to a stressor task (Slattery et al., 2013). Other physiological responses to stress (e.g., cardiovascular reactivity) have also been shown to differ based on whether the stress is perceived as a challenge versus a threat (Seery, 2011; Seery, Weisbuch, \& Blascovich, 2009; Turner, Jones, Sheffield, Barker, \& Coffee, 2014), suggesting that subjective appraisals may modulate both endocrine and sympathetic arousal. Taken together, these findings further reinforce the importance of considering stress perception in models of stress functioning.

An important step in this line of investigation is to establish whether childhood adversity is associated with heightened perception of daily stressors, and whether this relationship mediates the association between adversity and cortisol levels. Higher perceptions of daily stress may lead to amplified hypothalamic-pituitary-adrenal (HPA) axis activity, and elevations in cortisol, as a result of being in a constant state of stress. Previous research suggests that cortisol levels fluctuate across days due to situational factors including subjective stress load from the prior, as well as the upcoming day (Hellhammer et al., 2007). Consistent with this, a study with adults found that appraisals of daily hassles impacted next day cortisol awakening responses, such that lower cortisol awakening response levels were only seen after days when hassles were appraised as stressful (Gartland, O'Connor, Lawtwon, \& Bristow, 2014). These findings suggest stress perception may be salient to HPA axis activity and reflected in next day cortisol patterns.

Assuming perceptions of and reactions to stress are shaped by the characteristics of early environments, it stands to reason that adversity type may be relevant to delineating the associations between childhood adversity and stress indices. Most studies employ generalized risk approaches that include subjects with varied histories of sexual abuse, physical abuse, neglect, and poverty in one sample. A critical assumption here is that different types of adversity uniformly impact outcomes, and thus are exchangeable. However, there is preliminary evidence that 
different types of childhood adversity, and stressors more broadly, may have distinct consequences on the stress response system (Busso, McLaughlin, \& Sheridan, 2017; Kuhlman, Geiss, Vargas, \& Lopez-Duran, 2015; Miller, Chen, \& Zhou, 2007). For example, a large meta-analysis by Miller et al. (2007) found that stressors characterized by threat of harm and/or traumas were uniquely associated with a high, flat diurnal profile of cortisol secretion. A recent study in adolescents with a history of childhood adversity also found differential associations among subtypes of childhood adversity and indices of HPA axis functioning (e.g., diurnal rhythm, reactivity, and recovery; Kulhman et al., 2015). Different types of adversity may also have unique effects on the development of locus of control, self-efficacy, coping strategies, and schemas that influence stress appraisals (Chorpita \& Barlow, 1998; Jerusalem \& Schwarzer, 1992). These findings suggest that the nature of adversity experiences pose different demands on stress processes that result in unique neuroendocrine and subjective perceptions and highlight the utility of distinguishing between different types of adversity when examining their associations with stress indices.

While several different approaches to categorizing adversity types have been utilized in the literature (e.g., dependent vs. independent, social vs. nonsocial, and physical abuse vs. emotional abuse), these categories often lack a theoretical rationale for why these experiences should predict different outcomes. However, a recent conceptual model outlined by McLaughlin, Sheridan, and Lambert (2014) that distinguishes and categorizes adversity experiences along dimensions of threat and deprivation may provide a more useful strategy. In this model, threat refers to interpersonal exposures that involve harm or threat of harm, such as physical and sexual abuse. In contrast, deprivation refers to exposures that reflect an absence of expected environmental inputs such as poverty, neglect, and limited psychosocial support. In contrast with generalized-risk models this differentiated "dimensions of adversity" approach posits that threat and deprivation may increase risk for poor outcomes through distinct biological and developmental processes. A recent study utilizing the dimensions of adversity framework found that threat, but not deprivation, was associated with attenuated cortisol reactivity following a stress induction task (Busso, McLaughlin, \& Sheridan, 2017), providing some of the first empirical evidence for the differentiation of these dimensions in stress processes. While threat and deprivation dimensions have face validity, and there is some evidence that the distinction may be a valid one, further empirical exploration is needed. Comparing generalized adversity and differentiated adversity models that distinguish between threat and deprivation will help us determine whether the nature of specific exposures uniquely impacts stress indices.

Finally, sex and age differences are documented throughout the stress literature and may moderate the impact of childhood adversity on stress processes. Females report higher levels of perceived stress when compared to males in response to both life events (Davis, Matthews, \& Twamley, 1999) and daily hassles (Almedia \& Kessler, 1998; Myin-Germeys, Krabbendam, Delespaul, \& van Os, 2004). Sex differences in biological indices of HPA axis activity and stress reactivity have been less consistent and may depend on the nature of stressor presented (Kudielka \& Kirschbaum, 2005, Paris et al., 2010; Pruessner et al., 1997; Wüst, Federenko, Hellhammer, \& Kirschbaum, 2000). For example, there is some evidence that females show stronger biological responses to stressors that are interpersonal in nature (Stroud, Salovey, \& Epel, 2002).
Developmental differences related to age and pubertal status are also observed in the stress literature. There are normative age-related increases in stress reactivity and sensitivity to emotional stimuli during the transition from middle childhood to adolescence related to pubertal development and the activation of gonadal hormones (Andersen \& Teicher, 2008; Romeo \& McEwen, 2006; Spear, 2009; Walker, Sabuwalla, \& Huot, 2004). Increases in both basal cortisol levels and cortisol response to stress inductions are observed across this developmental period (Gunnar, Wewerka, Frenn, Long, \& Griggs, 2009). Similarly, perceived daily stress increases through adolescence, then appears to decline and stabilize in healthy youth at the age of 18 (Trotman et al., 2014). Another study found that stress perception increases in early to middle adolescence (12-15 years), and then decreases during the transition to adulthood (Seiffge-Krenke, Aunola, \& Nurmi, 2009). This pattern aligns with research on age differences in coping capacities, which has found that middle adolescence (15 to 17 years old) represents a turning point during which youth utilize more adaptive coping strategies as a function of cognitive maturation (Zimmer-Gembeck \& Skinner, 2011). These findings point to early to middle adolescence as a developmental period during which the effects of childhood adversity on stress functioning may be amplified.

\section{Current Study}

The current study investigated the links between childhood adversity, stress perception, and a biological index of HPA axis function (i.e., salivary morning cortisol), and examined whether stress perception mediates the association between childhood adversity and morning cortisol. Heightened stress perception may be a key consequence of childhood adversity that perpetuates stress vulnerability and continues to impact day-to-day HPA axis functioning. Accordingly, we hypothesized that childhood adversity would have an indirect effect on morning cortisol through stress perception. Given evidence that different types of adversity may have unique effects on stress processes, we compared a generalized and differentiated adversity model (threat vs. deprivation). Based on the principles of functional adaptation models (e.g., the active calibration model), we predicted that associations between childhood adversity and stress measures would be stronger for threat exposures. Early experiences of danger and threat of harm are likely to pose more significant functional demands on developing threat detection and coping processes related to stress perception, as well as greater HPA axis dysregulation (Busso, Mclaughlin, Brueck, et al., 2017). We also examined whether adversity-stress associations were moderated by sex and age. Given the evidence of increased stress vulnerability in females, we predicted that sex would moderate the associations between childhood adversity and stress measures, with stronger effects observed in females. Finally, we predicted that age would also moderate these associations. Given the normative developmental changes in stress responsivity and coping capacities during adolescence, we expected the associations between childhood adversity and stress measures to be stronger in our younger participants.

We utilized a large sample that included individuals at clinicalhigh risk (CHR) for serious mental illness, who are identified on the basis of subthreshold psychotic symptoms. The CHR population is ideally suited to test the effects of childhood adversity as these samples are enriched for adversity experiences and allow for a wider variation of adversity than what is typically afforded 
by community samples (Bendall, Jackson, Hulbert, \& McGorry, 2007; Larsson et al., 2013; Matheson, Shepherd, Pinchbeck, Laurens, \& Carr, 2013; Read, van Os, Morrison, \& Ross, 2005, Ruby et al., 2014). In addition to subthreshold positive symptoms, $80 \%$ of CHR individuals have comorbid diagnoses of mood, personality, and externalizing disorders that are independent of psychosis outcome (Addington et al., 2017). While about 20\%$30 \%$ go on to manifest a psychotic disorder, even more develop major depression and bipolar disorder (Fusar-Poli, Nelson, Valmaggia, Yung, \& McGuire, 2014).

\section{Method}

\section{Sample}

The sample included 605 individuals between 12 and 30 years of age $($ mean $=19.2, S D=4.5)$. All participants were recruited as part of the North American Prodrome Longitudinal Study, which identifies individuals at CHR for developing psychosis. Specific details about ascertainment and inclusion and exclusion criteria have been described in detail elsewhere (Addington et al., 2012). Of the 605 participants, 423 (70\%) met CHR criteria for serious mental illness; $182(30 \%)$ did not meet the criteria for CHR status. Participants were included in the current study if measures of childhood adversity exposure, salivary cortisol, and stress perception were collected at the baseline visit.

\section{Measures}

\section{Threat exposure}

Threat was operationalized to denote adverse experiences involving harm or threat of harm to an individual. Specific types of threat exposures were assessed using the Documentation of Trauma Form, a semistructured interview that retrospectively assesses six types of negative childhood experiences before the age of 16. Participants where asked whether they had experienced the following: emotional abuse (e.g., "unjustified punishment" or "being sworn at"), physical abuse (e.g., "being kicked or punched"), psychological bullying (e.g., "taunted or sworn at by peers"), physical bullying (e.g., "physically assaulted at school"), and sexual abuse (e.g., "touched sexually against will" or "sexual contact against will"). Responses were rated on a categorical "present" or "absent" scale. A threat composite score was created by summing responses to the physical abuse, sexual abuse, emotional abuse, physical bullying, and psychological bullying items. The threat composite score ranged from 0 (no endorsement of threat exposures) to 5 (endorsement of all threat exposures), and was used in all statistical analyses to capture variation in threat exposures.

\section{Deprivation exposure}

Deprivation was operationalized to denote experiences involving the absence of expected cognitive and social inputs. In the current study, deprivation items included indices of childhood poverty, emotional neglect, parental absence, and restricted peer relationships during childhood. Poverty was determined by the ratio of income to needs, which was computed by dividing reported family of origins income by US Census 2014 poverty line for a family of that size, with a value of $<1$ indicating that a family was living below the poverty line. A dichotomous measure of poverty was used rather than the linear income-to-needs ratio because it is unlikely that deprivation of inputs exist at the higher end of income distribution. Neglect was assessed via the neglect item (e.g., "not able to find any attention or support from people at home") on the Documentation of Trauma Form described above. Restricted peer interactions (a proxy of psychosocial deprivation) was determined using the social subscales of the Premorbid Adjustment Scale (Cannon-Spoor, Potkin, \& Wyatt, 1982), a widely used semistructured interview designed to retrospectively assess social and academic functioning across development. Interviewers rated participants on a 7-point scale for peer relationships during childhood (age 5-11 years). Scores falling between 4 and 6 , which indicate social isolation and lack of sameaged peer relationships, were used to indicate restricted peer relationships. Finally, absence of a biological parental figure (e.g., no/ minimal contact) was determined from a demographic information interview. A deprivation composite score was created by summing items of childhood poverty, childhood peer relations, parental absence, and neglect. This deprivation composite ranged from 0 (no endorsement of deprivation exposures) to 4 (endorsement of all deprivation exposures), and was used in all statistical analyses to capture variation in deprivation exposures.

\section{Salivary cortisol}

Basal cortisol levels were measured rather than acute cortisol reactivity given concerns about adverse effects of stress-induction paradigms on participants at risk for psychopathology. In addition, numerous animal and human studies have demonstrated that basal cortisol levels are associated with cortical volume, cognitive performance, and behavior, and it is assumed that these relations reflect the adverse effects of cortisol exposure that contribute to risk for psychopathology (for reviews see Lupien et al., 2009; Lupien, Ouellet-Morin, Herba, Juster, \& McEwen, 2016). Cortisol $(\mu \mathrm{g} / \mathrm{dL})$ concentrations were assessed via salivary samples during a baseline assessment in the research clinic. Salivary samples were collected using the drool method, whereby participants expectorate approximately $1.5 \mathrm{~mL}$ of saliva into a tube. Multiple saliva samples $(n=3)$ were obtained to derive an average and increase the reliability of the cortisol estimate. Cortisol levels were measured in the morning in order to minimize the cumulative effects of extraneous factors, such as food and activity level, that accrue through the day and have been shown to influence cortisol measurement (Kudielka, Hellhammer, \& Wust, 2009; Kudielka, Schommer, Hellhammer, \& Kirschbaum, 200;). Samples were collected approximately on the hour, beginning on average about 10:00 a.m., with a range from 9:00 a.m. to 11:30 a.m. at onset of sampling $(S D=26 \mathrm{~min})$. Saliva samples were immediately stored in a $-20{ }^{\circ} \mathrm{C}$ freezer until they were shipped on dry ice to a laboratory in Atlanta, Georgia. In preparation for assay, samples were rapidly thawed and centrifuged. All samples were assayed for salivary cortisol ( $\mu \mathrm{g} / \mathrm{dL})$ using a highly sensitive enzyme immunoassay (Salimetrics, State College, Pennsylvania). The test uses about $25 \mu \mathrm{L}$ of saliva (for singlet determinations), has a range of sensitivity from .007 to $1.8 \mathrm{mg} /$ $\mathrm{dL}$, and has average intra-assay and interassay coefficients of variation of less than $10 \%$ and $15 \%$. All samples were assayed in duplicate.

\section{Stress perception}

Stress perception was operationalized as perceived stressfulness of daily hassles. The Daily Stress Inventory is a 58-item measure of minor, common daily hassles occurring within the past $24 \mathrm{hr}$. Examples of such items include "was interrupted during task/ activity," "was criticized," and "had your sleep disturbed." 
Participants indicated if the event occurred and rated each endorsed event on a 7-point Likert scale ranging from occurred, but was not very stressful to caused me to panic. An index of stress perception was computed by regressing the total sum of stress ratings on the number of daily stress items endorsed. This method distinguishes among individuals who report the same number of exposures, but who differ in their subjective stress appraisals.

\section{Data analyses}

Consistent with findings of elevated rates of childhood adversity among youth at risk for psychosis, CHR youth endorsed higher levels of threat, $(F(1,603)=95.40 p<.01$, deprivation, $F(1$, $603)=77.20, p<.01$, and generalized adversity, $F(1,603)=$ $119.84, p<.01$, exposures. CHR youth also had higher levels of stress perception compared to healthy controls, $F(1,603)=$ 24.97, $p<.01$; however, these group differences were no longer significant when adversity exposure was controlled for. There were no group differences in morning cortisol, $F(1,603)=0.16$, $p=.69$. Analyses were conducted on the entire sample in order to include variation in childhood adversity exposure, stress measures, and psychopathology. However, group status (CHR vs. healthy control) was included in all analyses to control for diagnostic group effects on the proposed associations.

Path models were constructed to examine the associations between childhood adversity, stress perception, and morning cortisol using software package Mplus version 5.21 (Muthen \& Muthen, 2010). Childhood adversity, stress perception, and age variables were standardized prior to analyses. We estimated a generalized adversity model, which aggregates all adversity exposures into a single score, and compared it to a differentiated adversity model, which categorizes adversity exposures along dimensions of threat and deprivation. In the differentiated adversity model, both threat and deprivation were entered into the model, which allowed us to examine the effect of each adversity dimension (e.g., threat), while controlling for the effect of the other (e.g., deprivation). To test for mediation across all models, both direct and indirect effects were examined. The significance of indirect effects was tested using a bootstrapping approach (Hayes, 2013). To test for moderation, interaction terms were created by multiplying two standardized variables (e.g., Age $\times$ Threat). Main effect and interaction terms (sex and age) were included on all pathways. In the generalized risk model, a total of 6 interaction terms were modeled simultaneously; 10 interaction terms were modeled in the differentiated adversity model. The significance of the interaction term was used to determine whether moderation occurred. To ensure that co-occurring psychopathology did not confound associations, all models controlled for CHR group status.

For both the generalized and the differentiated-adversity approaches, we estimated two models. The first path model included interaction terms for sex and age on all pathways to examine whether stress perception mediated the association between adversity and morning cortisol, and whether these pathways were moderated by sex or age. The second path model was modified to only include the significant interaction terms observed in first model.

Prior to analyses, we tested whether cortisol sample timing was related to variables of interest (i.e., adversity exposure, stress perception, and CHR status) and found no significant associations. Due to diurnal changes and the relation between sampling time and cortisol levels, cortisol samples were adjusted for time of day collection by using a residualized score. A log transformation was applied to normalize the distribution of cortisol, a standard procedure with cortisol data (Miller \& Plessow, 2013). Statistical significance was based on $p<.05$, and all tests were two-tailed. Standardized betas are presented in results; unstandardized betas are reported for tests of simple slopes.

\section{Results}

\section{Sample characteristics}

Demographic and adversity characteristics are shown in Table 1. The majority of individuals in the current study reported at least one adversity exposure $(74 \% ; n=448)$. Across the entire sample, $59 \%(n=357)$ endorsed at least one threat exposure and $54 \%$ $(n=328)$ endorsed at least one deprivation exposure during childhood. Co-occurring adversities were common, with $49 \%(n=300)$ of individuals reporting two or more adversity exposures. Females endorsed higher levels of total adversity exposure, $F(1,603)=5.4$, $p=.02$, and threat exposure, $F(1,603)=4.23, p=.04$, compared to males. There were no sex differences in deprivation exposures, $F(1,603)=4.01, p=.06$, stress perception, $F(1,603)=0.68$, $p=.41$, or morning cortisol, $F(1,603)=0.09, p=.75$. There was a significant age difference in morning cortisol, $F(1,603)=$ $1.74, p<.01$, whereby cortisol increased with age, consistent with previous reports (Walker et al., 2013). A moderate correlation was observed between threat and deprivation $(r=.46, p<$ $.01)$ in the total sample, which is consistent with the literature on the co-occurrence rates among different types of adversity (Green et al., 2010). However, this modest correlation also suggests a degree of independence of the two adversity dimensions.

Bivariate and partial correlations between adversity dimensions and stress measures stratified by sex are presented in Table 2. In females, generalized adversity $(r=.35, p<.01)$ and threat $(r=.22, p<.01)$ were associated with stress perception; in males, deprivation $(r=.12 p<.02)$ was associated with stress perception. Stress perception was associated with cortisol in females $(r=.16, p<.01)$ but not in males. Cortisol was not associated with any indices of adversity for either sex. Age was associated with deprivation $(r=.13, p<.01)$, generalized adversity $(r=.10, p<.01)$, and morning cortisol $(r=.15, p<.01)$.

\section{Generalized adversity path models}

We first constructed a path model including sex and age interaction terms on all pathways to determine if stress perception mediated the association between generalized adversity and morning cortisol, and whether sex and age moderated these associations. This model (Figure 1) accounted for $6 \%$ of the variance in stress perception and $13 \%$ of the variance in morning cortisol. Sex moderated the association between generalized adversity and stress perception $(\beta=-.15, p=.01)$, but not the associations between generalized adversity and cortisol $(\beta=-.02, p=.74)$ or stress perception and cortisol $(\beta=.01, p=.87)$. For females only, higher levels of generalized adversity were associated higher levels of stress perception (simple slopes: $b=.15, p<.01$ ). Age did not moderate any of the associations; however, there was a direct effect of age on morning cortisol $(\beta=.19, p<.01)$, such that older individuals had higher cortisol levels. There were no direct effects of generalized adversity on morning cortisol stress $(\beta=-.04, p=.47)$ or stress perception on morning cortisol $(\beta=.10, p=.16)$, so indirect effects were not estimated. 
Table 1. Sample characteristics $(n=605)$

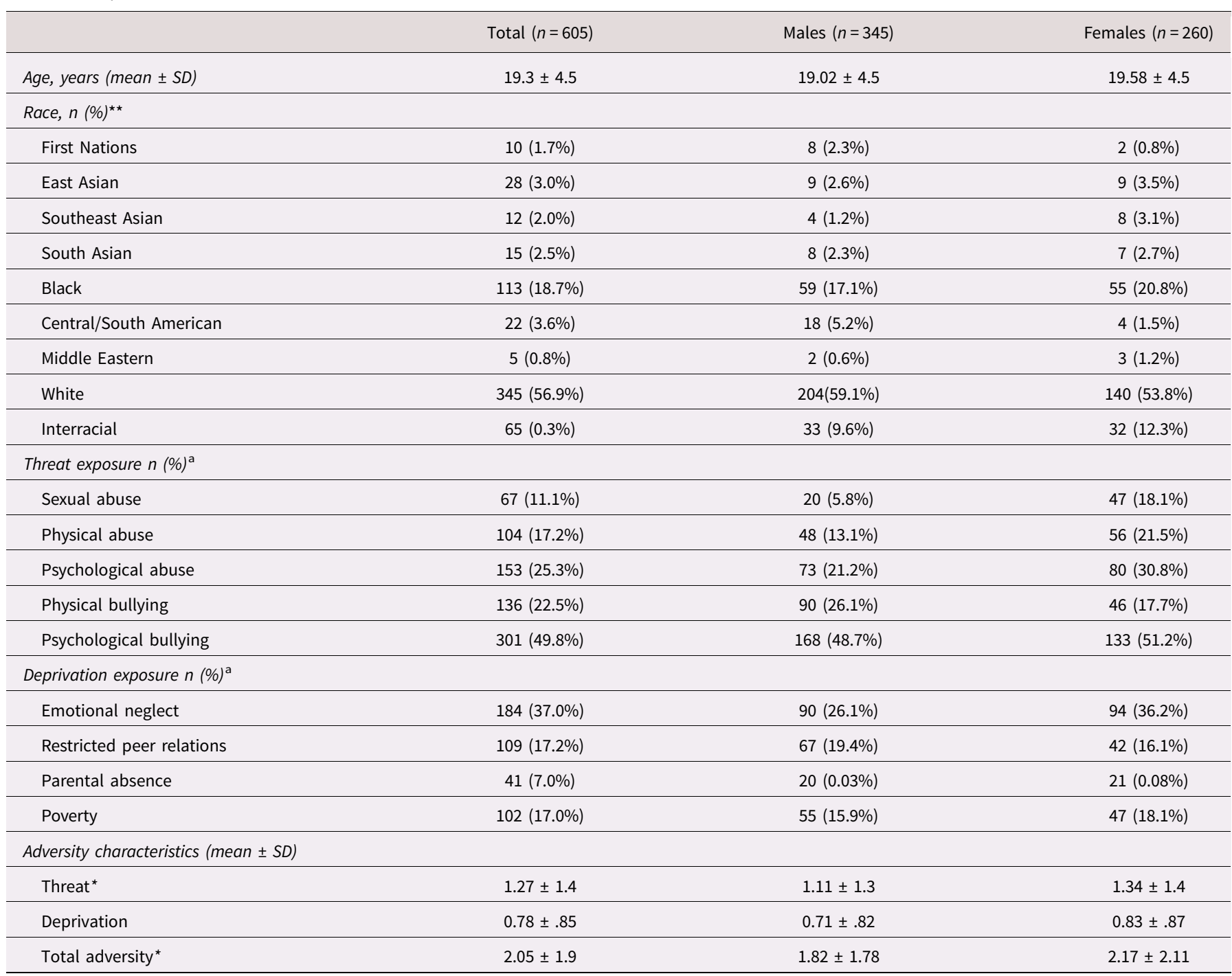

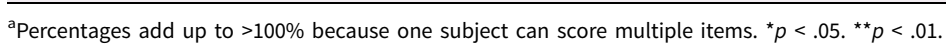

Table 2. Partial correlations for adversity exposure and stress measures

\begin{tabular}{|c|c|c|c|c|c|c|}
\hline & \multicolumn{3}{|c|}{ Stress perception } & \multicolumn{3}{|c|}{ Cortisol $^{\mathrm{b}}$} \\
\hline & Males $r$ & Females $r$ & Total $r$ & Males $r$ & Females $r$ & Total $r$ \\
\hline Threat & -.02 & $.22^{\star \star}$ & $.10^{*}$ & .01 & .09 & .05 \\
\hline Deprivation & $.12^{*}$ & .10 & $.13^{\star \star}$ & -.03 & .05 & .04 \\
\hline
\end{tabular}

Note: Correlations for threat control for deprivation; correlations for deprivation control for threat. There was a significant two-tailed correlation between threat and deprivation (males: $r=.40$, females: $r=.51$, total sample: $r=.46$ ). ${ }^{\mathrm{a}}$ Generalized adversity equals sum of threat and deprivation. ${ }^{\mathrm{b}}$ Correlations with cortisol control for saliva sampling time. ${ }^{\star} p<.05$. ${ }^{\star \star} p<.01$.

Next, we estimated a modified generalized adversity model that only included the significant interaction terms. This model (Figure 2) accounted for $8 \%$ of the variance in stress perception and $15 \%$ of the variance in morning cortisol. Sex moderated the association between generalized adversity and stress perception $(\beta=-.22, p<.01)$. For females only, higher levels of generalized adversity were associated with higher levels of stress perception (simple slopes: $b=.17 p<.01$ ). Consistent with the previous model, there was no direct effect of generalized adversity on morning cortisol $(\beta=-.04, p=.41)$; however, there was a direct effect of stress perception on morning cortisol $(\beta=.11, p=.04)$. There was also an indirect effect in females of generalized adversity on morning cortisol through stress perception, $b=.01$, $S E=.005,95 \%$ confidence interval $[.002, .023]$. 


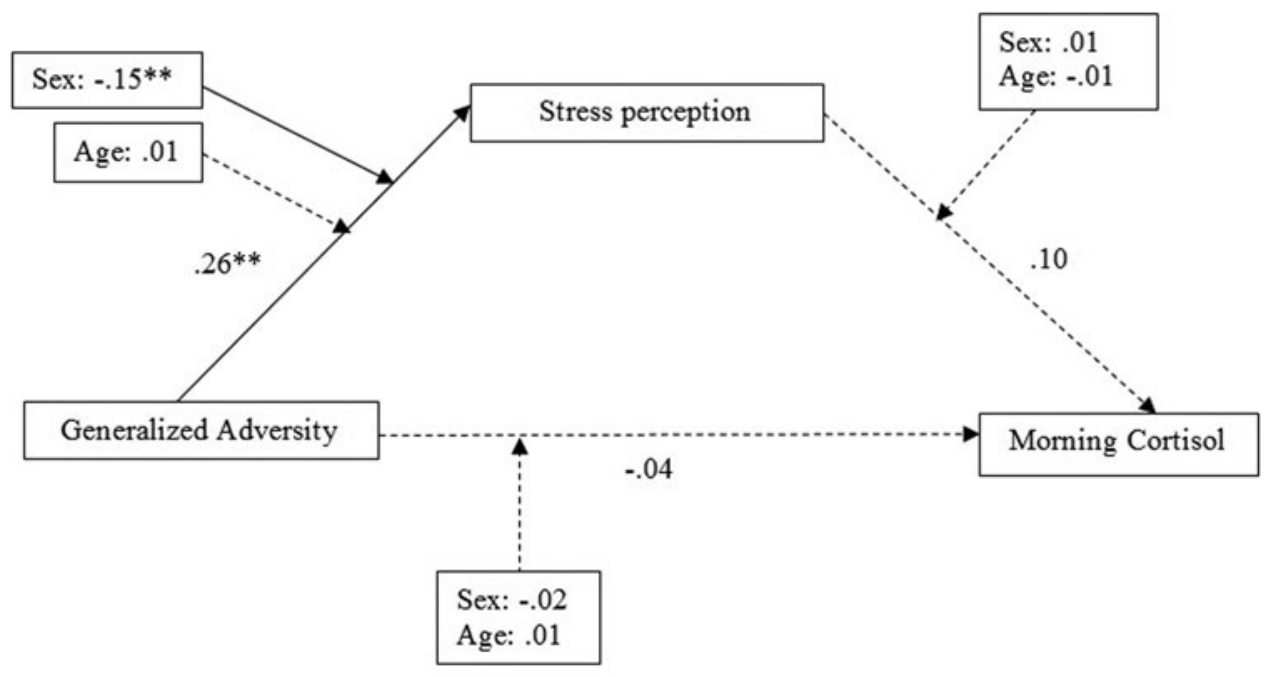

(Controlling for CHR group status)

Figure 1. Generalized adversity interaction path model examining the mediating effect of stress perception on the association between generalized adversity and morning cortisol. Paths are marked with standardized coefficients. ${ }^{\star \star} p<.01$.

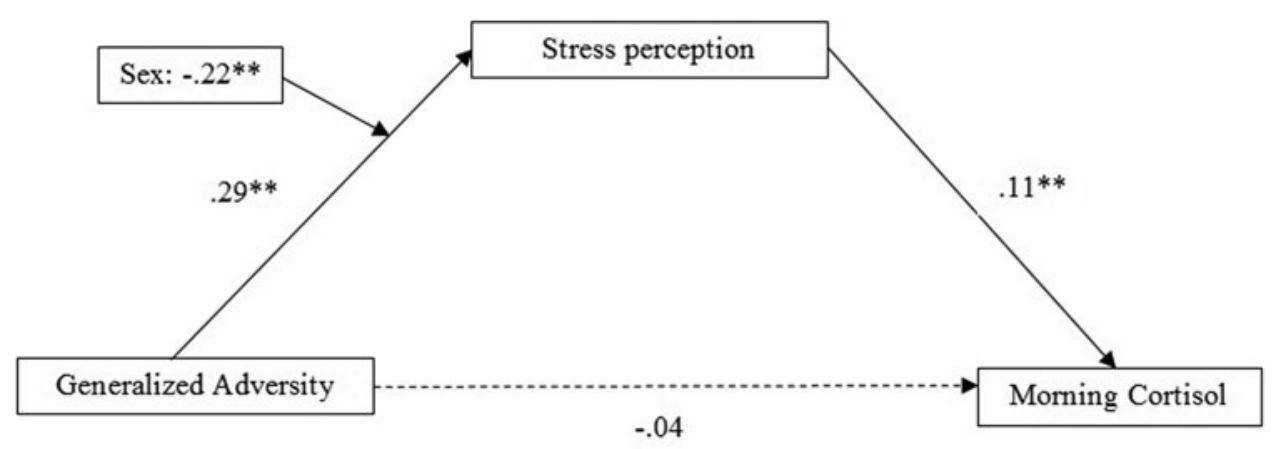

(Controlling for CHR group status)

Figure 2. Generalized adversity modified path model examining the mediating effect of stress perception on the association between generalized adversity and morning cortisol. Paths are marked with standardized coefficients. Indirect effect of generalized adversity on morning cortisol through stress perception in females (Indirect Estimate: $b=.01, \mathrm{SE}=.005,95 \% \mathrm{Cl}[.002-.023]$ ). ${ }^{\star *} p<.01$.

\section{Differentiated adversity path models}

We then examined the associations among childhood adversity, stress perception, and morning cortisol in a differentiated model that estimated threat and deprivation separately. In the first model, sex and age interaction terms were included on all pathways. This model (Figure 3) accounted for $9 \%$ of the variance in stress perception and $14 \%$ of the variance in morning cortisol. Sex moderated the association between threat and stress perception $(\beta=-.10, p<.01)$, but not the association between deprivation and stress perception $(\beta=.01, p=.85)$. For females only, higher levels of threat were associated with higher levels of stress perception (simple slopes: $b=.20, p<.01$ ). Sex did not moderate the associations between threat and morning cortisol $(\beta=-.01$, $p=.34)$, deprivation and morning cortisol $(\beta=.04, p=.51)$, or stress perception and morning cortisol $(\beta=.00, p=.98)$. Age did not moderate any of the associations; however, there was a direct effect of age on morning cortisol $(\beta=.19, p<.01)$, such that older individuals had higher cortisol levels. There were no direct effects of threat $(\beta=.01, p=.84)$, deprivation $(\beta=-.04$, $p=.53)$, or stress perception $(\beta=.11, p=.09)$ on morning cortisol, so indirect effects were not estimated.

Finally, we estimated a modified differentiated adversity model that only included the significant interaction term. This model (Figure 4 ) accounted for $10 \%$ of the variance in stress perception and $14 \%$ of the variance in morning cortisol. Sex moderated the association between threat and stress perception $(\beta=-.19, p<$ $.01)$. For females only, higher levels of threat predicated increased levels of stress perception (simple slopes: $b=.21, p<.01$ ). Consistent with the previous model, there was no direct effect of threat $(\beta=.02, p=.79)$ nor deprivation $(\beta=-.05, p=.51)$ on morning cortisol; however, there was a direct effect of stress 


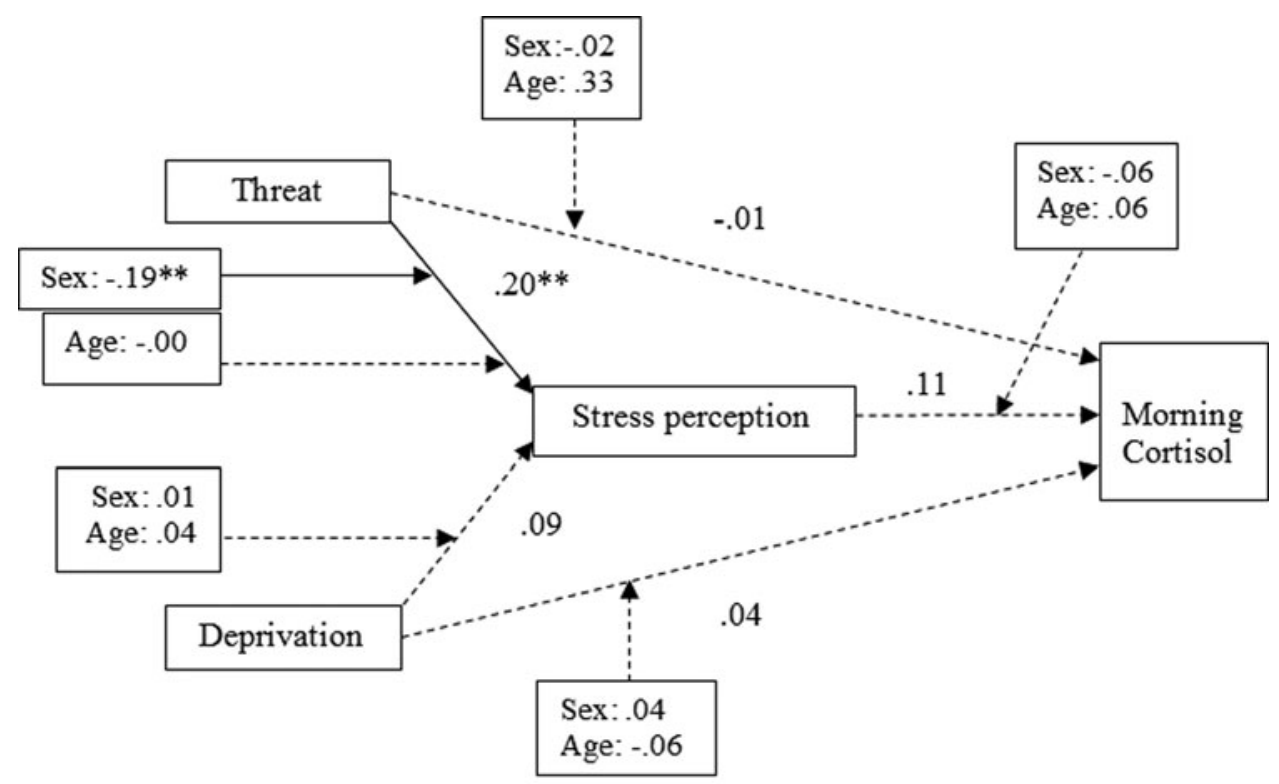

(Controlling for CHR group status)

Figure 3. Differentiated adversity interaction path model examining the mediating effect of stress perception on the association between threat, deprivation, and morning cortisol. Paths are marked with standardized coefficients. ${ }^{\star \star} p<.01$.

Figure 4. Differentiated adversity modified path model examining the mediating effect of stress perception on the association between threat, deprivation, and morning cortisol. Paths are marked with standardized coefficients. Indirect effect of threat on cortisol through stress perception in females (Indirect Estimate: $b=.02, \mathrm{SE}=.00,95 \% \mathrm{Cl}[.004-.032]) .{ }^{\star \star} p<.01$.

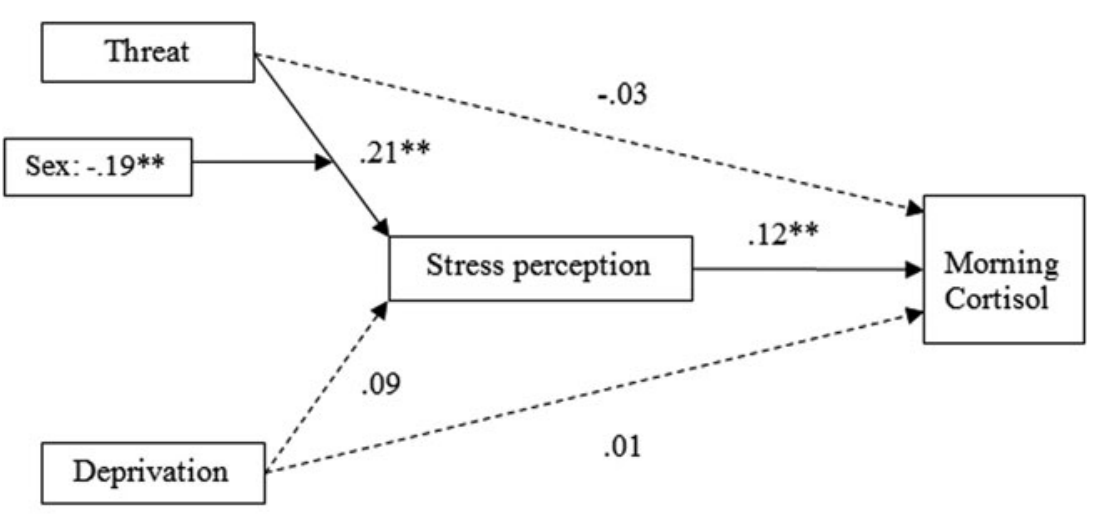

(Controlling for CHR group status) perception on morning cortisol $(\beta=.12, p=.01)$. There was also an indirect effect in females only of threat on morning cortisol through stress perception, $b=.02, S E=.00,95 \%$ confidence interval $[.004, .032]$.

\section{Discussion}

We investigated the relationship between childhood adversity, stress perception, and morning cortisol and examined whether these associations varied by adversity type, sex, and age. Childhood adversity was associated with increased stress perception, which subsequently predicted higher morning cortisol levels. However, this association was specific to threat exposures in females. The differentiated adversity model distinguishing between threat and deprivation highlighted the specificity of threat exposures, which was obscured in the generalized adversity model. Age did not moderate any of the adversity and stress associations. All models controlled for psychopathology (CHR status), suggesting that these finding are not simply a consequence of risk status and may constitute a more general risk process in females. Taken together, our finding suggest females with childhood histories of threat exposure may experience heighted stress perception later in life, which may confer an enduring vulnerability to stressrelated disorders.

Childhood adversity, specifically threat exposure, was associated with increased stress perception in females. Our findings are consistent with previous work documenting a relationship between childhood adversity and subjective perceptions of stress in adulthood (Gibson et al., 2014; McLaughlin et al., 2010; Rössler et al., 2016), but extend the literature by highlighting relevant adversity type and sex differences. While the exact 
mechanisms underlying these associations are unknown, there is basis for speculation. Given that the findings were specific to threat, it is important to consider why these types of exposures, as opposed to deprivation, are associated with stress perception.

From a functional adaptation perspective, heightened stress perception may develop as a response to threatening environments, via heightened threat detection and limited coping resources (Wadsworth, 2015). In the face of acute harm or danger, heighted threat detection and avoidant-coping strategies are likely to be adaptive. Approach-oriented coping (i.e., attempt to act or modify stressors through cognitive or overt behavior) may actually increase risk of danger or harm in threatening environments. Thus, heightened threat detection and coping strategies that protect a child from danger may become favored and established, at the expense of flexible coping strategies (i.e., problem solving) that are more adaptive when facing mild and normative stressors (Blair \& Raver, 2012; Masten \& Cicchetti, 2010). As a result, individuals with threat histories may develop a heightened perception of threat, and limited coping repertoires, which are a mismatch with the normative daily stressors they face later in life. Heighted attention to potential threats and the use of avoidant coping strategies have both been associated with both increased neuroendocrine activity and higher levels of perceived stress (Aldwin \& Yancura, 2004; Cramer, 2003; Jerusalem \& Schwarzer, 1992). While deprivation exposures may impact coping capacities, the presence of danger and harm in threat experiences may pose stronger demands for adaptation on coping resources. In addition, the nature of deprivation exposures is less likely to impact the calibration of threat detection systems (Busso, McLaughlin, Brueck, et al. 2017).

Threat experiences may also be more strongly linked to beliefs about helplessness, self-efficacy, safety, and control, which will influence an individual's assessment of their ability to handle situational demands. Of note, psychological abuse was the most common threat exposure in our sample. In this type of abuse, explicit negative messages that undermine the child's abilities, efficacy, and self-worth are directly supplied to the abuser. Future work is needed to elucidate the cognitive and biological processes through which threat exposures influence stress perception.

Our findings add to a growing body of literature for distinct effects of threat and deprivation (Busso, McLaughlin, \& Sheridan, 2017; Dennison et al., 2017; Lambert, King, Monahan, \& McLaughlin, 2017; Sheridan et al., 2018). While the generalized adversity approach is commonly utilized in the literature (Evan et al., 2013), our threat-specific findings highlight the limitations of this approach. By comparing the generalized and differentiated-adversity models, we were able to detect unique effects of threat. Previous studies that have grouped all adversity exposures into a single sum score have likely masked unique associations between different categories of adversity and outcomes. As the field looks to elucidate specific mechanisms linking adversity to psychopathology, it will be important to consider the specific nature of adversity experiences and the different functional demands they pose on developing systems.

The association between threat and stress perception was specific to females, which is consistent with the higher rates of stressrelated forms of psychopathology (e.g., depression and posttraumatic stress disorder) observed in females compared to males (Bangassar \& Valentino, 2014). Although the effects are small, these findings raise important questions regarding what factors underlie these observed sex differences. There are a number of possible explanations ranging from sex differences in fear circuitry, to the nature of threat experiences, to reporting biases. For example, sex differences are observed across development in the neurobiology of corticolimbic fear circuitry, such that females show poorer discrimination between danger and safety signals (Gamwell et al. 2015), heightened physiological and neural perception to threat cues (Domes et al., 2010; Lebron-Milad et al., 2012; Stevens \& Hamann, 2012; Tolin \& Foa, 2006), and lower thresholds for threat detection (Glover et al., 2012). Consistent with evidence that females are more sensitive than males to stressors that are interpersonal in nature (Stroud et al., 2002), the strong interpersonal quality of threat experiences, as opposed to deprivation, may increase the potency of threat exposures in females.

Alternatively, these sex differences may be accounted for by differences in the nature of threat experienced by females relative to males. In the current sample, females endorsed higher rates of sexual abuse, physical abuse, and psychological abuse (but not physical bullying). While including sex in our models helps account for differences in severity (i.e., total threat severity), it does not control for differences in the specific types of threat exposures, which may ultimately prove important. Relatedly, sex differences in reporting of both childhood adversity and perceived stress may also underlie these associations. Females tend to endorse higher levels of childhood trauma even though, with the exception of sexual abuse, there are few sex differences in rates of physical abuse, psychological abuse, and neglect (Koenen \& Widom, 2009; Tolin \& Foa, 2006). Thus, the current study may underestimate threat exposure in males. In regards to subjective perceived stress reporting, a large meta-analysis concluded that there are robust sex differences in the appraisal of stressful events relative to actual stress exposures, with females endorsing higher levels of perceived stress (Davis et al., 1999). In our sample there were no sex differences in stress perception. More work is needed to tease apart whether these associations are driven by true sex differences in the way threat experiences shape subjective stress perception, or whether they are artifacts of severity differences and reporting tendencies.

Contrary to our hypothesis, age did not moderate any of the associations between adversity and stress processes. This is somewhat surprising given the normative increases in stress responsivity typically observed during adolescence (Gunnar et al., 2009; Trotman et al., 2014). However, our sample was composed primarily of postpubertal individuals, which may have limited our ability to detect developmental effects. Given the effect of gonadal hormones on developing stress systems, it would be helpful to examine differences in these associations in younger individuals (e.g., ages 9-11) who are earlier in the pubertal transition (Bale \& Epperson, 2015). In addition, the younger individuals in our sample had lower levels of adversity exposure, which may have also limited our ability to detect age effects. This is likely due to the fact that parental involvement and consent is required for participation of minors ( $<18$ years), but not for those aged 18 and above. Consistent with research on sensitive periods for stress exposure, it is also possible that developmental effects are more salient to the timing of adversity exposure than to the age at which these associations are assessed (Bosch et al., 2012; Lupien et al., 2009; Pesonen et al., 2010).

There were no direct effects of adversity exposure on morning cortisol levels in any of our models. This is not surprising given the complexities of estimating the association between history of childhood adversity and cortisol, particularly given the variability in the time lag between exposure and cortisol measurement 
(Gunnar \& Quivedo, 2007b; Miller et al., 2007; Tarullo \& Gunnar, 2006). In addition, differences in the chronicity of adversity exposures may be an important moderator in these associations. While some adversity exposures are more pervasive and chronic in nature, others are periodic and acute. These differences in chronicity may result in distinct patterns of hypercortisolim and hypocortisolism that are washed out in samples in which chronicity is not assessed. It is also possible that childhood adversity exerts direct long-term effects on other indices of HPA axis functioning not measured in this study, such as cortisol reactivity, early awakening response, and diurnal rhythm. The lack of direct effects of adversity on morning cortisol may also stem from differential susceptibility to the environment. Accumulating research suggests that genetic factors and early adversity operate in concert to instantiate vulnerability and predict negative outcomes later in life (Ellis et al., 2011; Pluess, 2015; Pluess \& Belsky, 2011; Pluess, Stevens, \& Belsky, 2013). Consistent with this, a number of genotypes implicated in Gene $\times$ Environment studies have been found to moderate the effects of early adversity on HPA axis reactivity (Cicchetti, Rogosch, \& Oshri, 2011; Heim et al., 2009; Tyrka et al., 2009). Thus, samples of adversity-exposed youth likely include individuals with different polygenic risk profiles, leading to inconsistencies in findings as a function of the sample's genetic makeup. In addition, protective factors such as social support and strong cognitive and social skills have also been shown to buffer the detrimental effects of childhood adversity (Collinshaw et al., 2007; Jaffee, Caspi, Moffit, Polo-Thomas, \& Taylor, 2007; Rutten et al., 2013). Future studies that include better characterization of genetic profiles and protective factors are needed to delineate the complex associations between childhood adversity and HPA axis function.

While there were no direct effects on morning cortisol, there was an indirect effect of threat on morning cortisol through stress perception in females. The effects are small and should be interpreted with caution. However, these findings provide preliminary evidence that childhood experiences of threat may have an indirect, but enduring, effect on stress systems via heightened sensitivity to day-to-day stressors among females. This interpretation is consistent with theories and evidence concerning greater female sensitivity to stress, particularly after puberty, due to the effects of gonadal hormones on the HPA axis (Bale \& Epperson, 2015). More work is needed to elucidate sex differences in the role of stress appraisals in modulating biological stress responses, and the relative concordance between those two measures.

Finally, we controlled for CHR status in all models, suggesting that our findings are not confounded by risk status. Although we did not look at psychiatric outcomes, heightened stress perception may be a plausible risk mechanism underlying the link between childhood threat experiences and mixed presentations of psychopathology. A recent study found that heightened stress perception was associated with later comorbid psychopathology in individuals with a trauma history (van Nierop et al., 2018). While prevention of childhood adversity is the ultimate goal, stress perception may be a critical and modifiable preventative intervention target to reduce negative outcomes following adversity experiences, especially for females.

The findings from this study should be considered in light of several limitations. All adversity indices were self-reported, retrospective, and categorical variables. The reliance of retrospective reporting of childhood adversity introduces the possibility of both under- and overreporting, which may have affected our results. While the categorical variables provide a rough estimate of exposure history, they do not include measures of frequency, intensity, or timing of specific exposure types (e.g., times of sexual abuse or intensity of physical abuse), which are likely to be important. In addition, the adversity experiences included in this study do not encompass all forms of threat (e.g., community violence and witnessing domestic abuse) or deprivation, nor do they include parental psychopathology or non-interpersonal forms of trauma (e.g., car accidents, injuries, and natural disasters). While childhood poverty in the deprivation domain was assessed using the federal poverty line, this is likely an underestimate of poverty at some sites, given the diversity in cost of living among the urban areas from which participants were drawn (i.e., Los Angeles, Atlanta, San Diego, Boston, and Chapel Hill). Future studies utilizing more extensive measures of threat and deprivation will be needed to replicate these findings. Although morning cortisol is one index of HPA axis activity, there are challenges to its measurement due to diurnal and circadian rhythms (Young \& Breslau, 2004). Finally, although our theoretical model implies a developmental sequence, our measures of self-reported childhood adversity, stress perception, and morning cortisol were assessed concurrently, and thus are not temporally ordered.

In sum, the current findings point to a complex relationship between childhood adversity and stress processes that varies by adversity dimension and sex. While subjective stress perception has received relatively little attention in the childhood adversity literature, it may be important to understanding the long-term impact of adversity exposure on subsequent stress processes and psychiatric vulnerability. The findings also highlight the importance of assessing specific types of adversity, as well as sex differences. Future work should continue to delineate both the biological and the cognitive pathways through which childhood experiences of threat and deprivation shape future perceptions of stress, and whether these differ by sex and age. This work will be critical to the development of preventative interventions following adversity exposure in childhood.

Acknowledgments. This work was supported by a collaborative U01 award from the National Institute of Mental Health at the National Institutes of Health (MH081902 to T.D.C.; MH081857 to B.A.C.; MH081988 to E.W.; MH081928 to L.J.S.; MH082004 to D.P. MH082022 to K.C.; MH081984 to J.A.; and MH082022 to S.W.W.) and NIMH P50 MH066286 and the Staglin Music Festival for Mental Health (to C.E.B.).

\section{References}

Addington, J., Cadenhead, K. S., Cornblatt, B. A., Mathalon, D. H., McGlashan, T. H., Perkins, D. O., ... Addington, J. A. (2012). North American prodrome longitudinal study (NAPLS 2): Overview and recruitment. Schizophrenia Research, 142, 77-82. doi:10.1016/j.schres.2012.09.012 Addington, J., Piskulic, D., Liu, L., Lockwood, J., Cadenhead, K. S., Cannon, T. D., ... Tsuang, M. T. (2017). Comorbid diagnoses for youth at clinical high risk of psychosis. Schizophrenia Research, 190, 90-95. doi:10.1016/ j.schres.2017.03.043

Aldwin, C. M., \& Yancura, L. A. (2004). Coping and health: A comparison of the stress and trauma literatures. In P. P. Schurr \& B. L. Green (Eds.), Trauma and health: Physical health consequences of exposure to extreme stress (pp. 99-125). Washington, DC: American Psychological Association.

Allwood, M., Gaffey, A., Vergara-Lopez, C., \& Stroud, L. (2017). Stress through the mind of the beholder: Preliminary differences in child and maternal perceptions of stress in relation to child cortisol and cardiovascular reactivity. International Journal on the Biology of Stress, 20, 341-349. doi:10.1080/ 10253890.2017.1336617 
Almeida, D. M., \& Kessler, R. C. (1998). Everyday stressors and gender differences in daily stress. Journal of Personality and Social Psychology, 75, 670680. doi:10.1037/0022-3514.75.3.670

Andersen, S. L., \& Teicher, M. H. (2008). Stress, sensitive periods and maturational events in adolescent depression. Trends in Neurosciences, 31, 183-191. doi:10.1016/j.tins.2008.01.004

Bale, T. L., \& Epperson, C. N. (2015). Sex differences and stress across the lifespan. Nature Neuroscience, 18, 1413. doi:10.1038/nn.4112

Bangasser, D. A., \& Valentino, R. J. (2014). Sex differences in stress-related psychiatric disorders: Neurobiological perspectives. Frontiers in Neuroendocrinology, 35, 303-319. doi:10.1016/j.yfrne.2014.03.008

Bendall, S., Jackson, H. J., Hulbert, C. A., \& McGorry, P. D. (2007). Childhood trauma and psychotic disorders: A systematic, critical review of the evidence. Schizophrenia Bulletin, 34, 568-579. doi:10.1093/schbul/sbm121

Blair, C., \& Raver, C. C. (2012). Child development in the context of adversity: Experiential canalization of brain and behavior. American Psychologist, 67, 309. doi:10.1037/a0027493

Bosch, N. M., Riese, H., Reijneveld, S. A., Bakker, M. P., Verhulst, F. C., Ormel, J., \& Oldehinkel, A. J. (2012). Timing matters: Long term effects of adversities from prenatal period up to adolescence on adolescents' cortisol stress response. The TRAILS study. Psychoneuroendocrinology, 37, 14391447. doi:10.1016/j.psyneuen.2012.01.013

Boyce, W. T., \& Ellis, B. J. (2005). Biological sensitivity to context: I. An evolutionary-developmental theory of the origins and functions of stress reactivity. Development and Psychopathology, 17, 271-301.

Busso, D. S., McLaughlin, K. A., Brueck, S., Peverill, M., Gold, A. L., \& Sheridan, M. A. (2017). Child abuse, neural structure, and adolescent psychopathology: A longitudinal study. Journal of the American Academy of Child \& Adolescent Psychiatry, 56, 321-328. doi:10.1016/j.jaac.2017.01.013

Busso, D. S., McLaughlin, K. A., \& Sheridan, M. A. (2017). Dimensions of adversity, physiological reactivity, and externalizing psychopathology in adolescence: Deprivation and threat. Psychosomatic Medicine, 79, 162171. doi:10.1097/PSY.0000000000000369

Cannon-Spoor, H. E., Potkin, S. G., \& Wyatt, R. J. (1982). Measurement of premorbid adjustment in chronic schizophrenia. Schizophrenia Bulletin, 8 , 470. doi:10.1093/schbul/8.3.470

Chen, Y., \& Baram, T. Z. (2016). Toward understanding how early-life stress reprograms cognitive and emotional brain networks. Neuropsychopharmacology, 41, 197-206. doi:10.1038/npp.2015.181

Chorpita, B. F., \& Barlow, D. H. (1998). The development of anxiety: The role of control in the early environment. Psychological Bulletin, 124, 3. doi:10.1037/0033-2909.124.1.3

Cicchetti, D., Rogosch, F. A., \& Oshri, A. (2011). Interactive effects of corticotropin releasing hormone receptor 1 , serotonin transporter linked polymorphic region, and child maltreatment on diurnal cortisol regulation and internalizing symptomatology. Development and Psychopathology, 23, 1125-1138. doi:10.1017/S0954579411000599

Collishaw, S., Pickles, A., Messer, J., Rutter, M., Shearer, C., \& Maughan, B. (2007). Resilience to adult psychopathology following childhood maltreatment: Evidence from a community sample. Child Abuse \& Neglect, 31, 211-229. doi:10.1016/j.chiabu.2007.02.004

Compas, B. E., Connor, J. K., Saltzman, H., Thomsen, A. H., \& Wadsworth, M. (1999). Getting specific about coping: Effortful and involuntary responses to stress in development. In M. Lewis \& D. S. Ramsay (Eds.), Soothing and stress (pp. 229-256). London: Psychology Press.

Cramer, P. (2003). Defense mechanisms and physiological reactivity to stress. Journal of Personality, 71, 221-244. doi:10.1111/1467-6494.7102001

Danese, A., Moffitt, T. E., Harrington, H., Milne, B. J., Polanczyk, G., Pariante, C. M., ... Caspi, A. (2009). Adverse childhood experiences and adult risk factors for age-related disease: Depression, inflammation, and clustering of metabolic risk markers. Archives of Pediatrics \& Adolescent Medicine, 163, 1135-1143. doi:10.1001/archpediatrics.2009.214

Davis, M. C., Matthews, K. A., \& Twamley, E. W. (1999). Is life more difficult on Mars or Venus? A meta-analytic review of sex differences in major and minor life events. Annals of Behavioral Medicine, 21, 83-97. doi:10.1007/BF02895038

Del Giudice, M., Ellis, B. J., \& Shirtcliff, E. A. (2011). The adaptive calibration model of stress responsivity. Neuroscience \& Biobehavioral Reviews, 35, 1562-1592. doi:10.1016/j.neubiorev.2010.11.007
Dennison, M. J., Rosen, M. L., Sambrook, K. A., Jenness, J. L., Sheridan, M. A., \& McLaughlin, K. A. (2017). Differential associations of distinct forms of childhood adversity with neurobehavioral measures of reward processing: A developmental pathway to depression. Child Development, 90, 96-113. doi:10.1111/cdev.13011

Dickerson, S. S., \& Kemeny, M. E. (2004). Acute stressors and cortisol responses: A theoretical integration and synthesis of laboratory research. Psychological Bulletin, 130, 355. doi:10.1037/0033-2909.130.3.355

Domes, G., Schulze, L., Böttger, M., Grossmann, A., Hauenstein, K., Wirtz, P. H., ... Herpertz, S. C. (2010). The neural correlates of sex differences in emotional reactivity and emotion regulation. Human Brain Mapping, 31, 758-769. doi:10.1002/hbm.20903

Ellis, B. J., Boyce, W. T., Belsky, J., Bakermans-Kranenburg, M. J., \& van IJzendoorn, M. H. (2011). Differential susceptibility to the environment: An evolutionary-neurodevelopmental theory. Development and Psychopathology, 23, 7-28. doi:10.1017/S0954579410000611

Evans, G. W., Li, D., \& Whipple, S. S. (2013). Cumulative risk and child development. Psychological Bulletin, 139, 1342-1396. doi:10.1037/a0031808

Folkman, S., Lazarus, R. S., Dunkel-Schetter, C., DeLongis, A., \& Gruen, R. J. (1986). Dynamics of a stressful encounter: Cognitive appraisal, coping, and encounter outcomes. Journal of Personality and Social Psychology, 50, 992. doi:10.1037/0022-3514.50.5.992

Fusar-Poli, P., Nelson, B., Valmaggia, L., Yung, A. R., \& McGuire, P. K. (2014). Comorbid depressive and anxiety disorders in 509 individuals with an at-risk mental state: Impact on psychopathology and transition to psychosis. Schizophrenia Bulletin, 40, 120-131. doi:10.1093/schbul/sbs136

Gaab, J., Blättler, N., Menzi, T., Pabst, B., Stoyer, S., \& Ehlert, U. (2003). Randomized controlled evaluation of the effects of cognitive-behavioral stress management on cortisol responses to acute stress in healthy subjects. Psychoneuroendocrinology, 28, 767-779. doi:10.1016/S0306-4530(02)00069-0

Gaab, J., Rohleder, N., Nater, U. M., \& Ehlert, U. (2005). Psychological determinants of the cortisol stress response: The role of anticipatory cognitive appraisal. Psychoneuroendocrinology, 30, 599-610. doi:10.1016/j.psyneuen. 2005.02.001

Gamwell, K., Nylocks, M., Cross, D., Bradley, B., Norrholm, S. D., \& Jovanovic, T. (2015). Fear conditioned responses and PTSD symptoms in children: Sex differences in fear-related symptoms. Developmental Psychobiology, 57, 799-808. doi:10.1002/dev.21313

Gartland, N., O'Connor, D. B., Lawton, R., \& Bristow, M. (2014). Exploring day-to-day dynamics of daily stressor appraisals, physical symptoms and the cortisol awakening response. Psychoneuroendocrinology, 50, 130-138. doi:10.1016/j.psyneuen.2014.08.006

Gibson, L. E., Anglin, D. M., Klugman, J. T., Reeves, L. E., Fineberg, A. M., Maxwell, S. D., ... Ellman, L. M. (2014). Stress sensitivity mediates the relationship between traumatic life events and attenuated positive psychotic symptoms differentially by gender in a college population sample. Journal of Psychiatric Research, 53, 111-118. doi:10.1016/j.jpsychires.2014.02.020

Glaser, J. P., van Os, J., Portegijs, P. J., \& Myin-Germeys, I. (2006). Childhood trauma and emotional reactivity to daily life stress in adult frequent attenders of general practitioners. Journal of Psychosomatic Research, 61, 229-236. doi:10.1016/j.jpsychores.2006.04.014

Glover, E. M., Jovanovic, T., Mercer, K. B., Kerley, K., Bradley, B., Ressler, K. J., \& Norrholm, S. D. (2012). Estrogen levels are associated with extinction deficits in women with posttraumatic stress disorder. Biological Psychiatry, 72, 19-24. doi:10.1016/j.biopsych.2012.02.031

Green, J. G., McLaughlin, K. A., Berglund, P. A., Gruber, M. J., Sampson, N. A., Zaslavsky, A. M., \& Kessler, R. C. (2010). Childhood adversities and adult psychiatric disorders in the national comorbidity survey replication: I. Associations with first onset of DSM-IV disorders. Archives of General Psychiatry, 67, 113-123. doi:10.1001/archgenpsychiatry.2009.186

Gunnar, M., \& Quevedo, K. (2007a). The neurobiology of stress and development. Annual Review of Psychology, 58, 145-173. doi:10.1146/ annurev.psych.58.110405.085605

Gunnar, M. R., \& Quevedo, K. M. (2007b). Early care experiences and HPA axis regulation in children: A mechanism for later trauma vulnerability. Progress in Brain Research, 167, 137-149. doi:10.1016/S0079-6123(07)67010-1

Gunnar, M. R., \& Vazquez, D. (2006). Stress neurobiology and developmental psychopathology. In D. Cicchetti \& D. J. Cohen (Eds.), Developmental 
psychopathology: Vol. 2. Developmental neuroscience (pp. 533-577). Hoboken, NJ: Wiley.

Gunnar, M. R., Wewerka, S., Frenn, K., Long, J. D., \& Griggs, C. (2009). Developmental changes in hypothalamus-pituitary-adrenal activity over the transition to adolescence: Normative changes and associations with puberty. Development and Psychopathology, 21, 69-85. doi:10.1017/ S0954579409000054

Hamman, C., Henry, R., \& Daley, S. E. (2000). Depression and sensitization to stressors among young women as a function of childhood adversity. Journal of Consulting and Clinical Psychology, 68, 782-787. doi:10.1037/0022006X.68.5.782

Hammerfald, K., Eberle, C., Grau, M., Kinsperger, A., Zimmermann, A., Ehlert, U., \& Gaab, J. (2006). Persistent effects of cognitive-behavioral stress management on cortisol responses to acute stress in healthy subjects-A randomized controlled trial. Psychoneuroendocrinology, 31, 333-339. doi:10.1016/j.psyneuen.2005.08.007

Harkness, K. L., Hayden, E. P., \& Lopez-Duran, N. L. (2015). Stress sensitivity and stress sensitization in psychopathology: An introduction to the special section. Journal of Abnormal Psychology, 124, 1-3. doi:10.1037/abn0000041

Hayes, A. F. (2013). Introduction to mediation, moderation, and conditional process analysis: A regression-based approach. New York: Guilford Press.

Heim, C., Bradley, B., Mletzko, T., Deveau, T. C., Musselmann, D. L., Nemeroff, C. B., ... Binder, E. B. (2009). Effect of childhood trauma on adult depression and neuroendocrine function: Sex-specific moderation by CRH receptor 1 gene. Frontiers in Behavioral Neuroscience, 3, 41. doi:10.3389/neuro.08.041.2009

Hellhammer, J., Fries, E., Schweisthal, O. W., Schlotz, W., Stone, A. A., \& Hagemann, D. (2007). Several daily measurements are necessary to reliably assess the cortisol rise after awakening: State-and trait components. Psychoneuroendocrinology, 32, 8086. doi:10.1016/j.psyneuen.2006.10.005

Hunter, A. L., Minnis, H., \& Wilson, P. (2011). Altered stress responses in children exposed to early adversity: A systematic review of salivary cortisol studies. Stress, 14, 614-626. doi:10.3109/10253890.2011.577848

Jaffee, S. R., Caspi, A., Moffitt, T. E., Polo-Tomas, M., \& Taylor, A. (2007). Individual, family, and neighborhood factors distinguish resilient from nonresilient maltreated children: A cumulative stressors model. Child Abuse \& Neglect, 31, 231-253. doi:10.1016/j.chiabu.2006.03.011

Jerusalem, M., \& Schwarzer, R. (1992). Self-efficacy as a resource factor in stress appraisal processes. In R. Schwarzer (Ed.), Self-efficacy: Thought control of action (pp. 195-213). Washington, DC: Hemisphere.

Juster, R. P., Perna, A., Marin, M. F., Sindi, S., \& Lupien, S. J. (2012). Timing is everything: Anticipatory stress dynamics among cortisol and blood pressure reactivity and recovery in healthy adults. Stress, 15, 569-577. doi:10.3109/ 10253890.2012.661494

Kelleher, I., Harley, M., Lynch, F., Arseneault, L., Fitzpatrick, C., \& Cannon, M. (2008). Associations between childhood trauma, bullying and psychotic symptoms among a school-based adolescent sample. British Journal of Psychiatry, 193, 378-382. doi:10.1192/bjp.bp.108.049536

Kessler, R. C., Green, J. G., Gruber, M. J., Sampson, N. A., Bromet, E., Cuitan, M., ... Lara, C. (2010). Screening for serious mental illness in the general population with the K6 screening scale: Results from the WHO World Mental Health (WMH) survey initiative. International Journal of Methods in Psychiatric Research, 19(Suppl. 1), 4-22. doi:10.1002/mpr.310

Koenen, K. C., \& Widom, C. S. (2009). A prospective study of sex differences in the lifetime risk of posttraumatic stress disorder among abused and neglected children grown up. Journal of Traumatic Stress, 22, 566-574. doi:10.1002/jts.20478

Kudielka, B. M., Hellhammer, D. H., \& Wüst, S. (2009). Why do we respond so differently? Reviewing determinants of human salivary cortisol responses to challenge. Psychoneuroendocrinology, 34, 2-18. doi:10.1016/j/psyneuen. 2008.10.004

Kudielka, B. M., \& Kirschbaum, C. (2005). Sex differences in HPA axis responses to stress: A review. Biological Psychology, 69, 113-132. doi:10. 1016/j.biopsycho.2004.11.009

Kudielka, B. M., Schommer, N. C., Hellhammer, D. H., \& Kirschbaum, C. (2004). Acute HPA axis responses, heart rate, and mood changes to psychosocial stress (TSST) in humans at different times of day. Psychoneuroendocrinology, 29, 983-992. doi:10.1016/j.psyneuen.2003. 08.009
Kuhlman, K. R., Geiss, E. G., Vargas, I., \& Lopez-Duran, N. L. (2015). Differential associations between childhood trauma subtypes and adolescent HPA-axis functioning. Psychoneuroendocrinology, 54, 103-114. doi:10.1016/j.psyneuen.2015.01.020

Lambert, H. K., King, K. M., Monahan, K. C., \& McLaughlin, K. A. (2017). Differential associations of threat and deprivation with emotion regulation and cognitive control in adolescence. Development and Psychopathology, 29, 929-940. doi:10.1017/S0954579416000584

Lardinois, M., Lataster, T., Mengelers, R., van Os, J., \& Myin-Germeys, I. (2011). Childhood trauma and increased stress sensitivity in psychosis. Acta Psychiatrica Scandinavica, 123, 28-35. doi:10.1111/j.1600-0447.2010.01594.x Larsson, S., Andreassen, O. A., Aas, M., Røssberg, J. I., Mork, E., Steen, N. E., ... Melle, I. (2013). High prevalence of childhood trauma in patients with schizophrenia spectrum and affective disorder. Comprehensive Psychiatry, 54, 123-127. doi:10.1016/j.comppsych.2012.06.009

Lazarus, R. S., \& Folkman, S. (1984). Coping and adaptation. In W. D. Gentry (Ed.), The handbook of behavioral medicine (pp. 282-325). New York: Guilford Press.

Lebron-Milad, K., Abbs, B., Milad, M. R., Linnman, C., RougemountBücking, A., Zeidan, M. A., ... Goldstein, J. M. (2012). Sex differences in the neurobiology of fear conditioning and extinction: A preliminary fMRI study of shared sex differences with stress-arousal circuitry. Biology of Mood \& Anxiety Disorders, 2, 7. doi:10.1186/2045-5380-2-7

Lengua, L. J., \& Long, A. C. (2002). The role of emotionality and selfregulation in the appraisal-coping process: Tests of direct and moderating effects. Journal of Applied Developmental Psychology, 23, 471-493. doi:10.1016/S0193-3973(02)00129-6

Lupien, S. J., McEwen, B. S., Gunnar, M. R., \& Heim, C. (2009). Effects of stress throughout the lifespan on the brain, behaviour and cognition. Nature Reviews Neuroscience, 10, 434-445. doi:10.1038/nrn2639

Lupien, S. J., Ouellet-Morin, I., Herba, C. M., Juster, R., \& McEwen, B. S. (2016). From vulnerability to neurotoxicity: A developmental approach to the effects of stress on the brain and behavior. In Epigenetics and neuroendocrinology (pp. 3-48). Cham, Switzerland: Springer.

Maier, S. F., Amat, J., Baratta, M. V., Paul, E., \& Watkins, L. R. (2006). Behavioral control, the medial prefrontal cortex, and resilience. Dialogues in Clinical Neuroscience, 8, 397.

Mandelli, L., Petrelli, C., \& Serretti, A. (2015). The role of specific early trauma in adult depression: A meta-analysis of published literature. Childhood trauma and adult depression. European Psychiatry, 30, 665-680. doi:10.1016/j.eurpsy.2015.04.007

Maniam, J., Antoniadis, C., \& Morris, M. J. (2014). Early-life stress, HPA axis adaptation, and mechanisms contributing to later health outcomes. Frontiers in Endocrinology, 5, 73. doi:10.3389/fendo.2014.00073

Masten, A. S., \& Cicchetti, D. (2010). Developmental cascades. Development and Psychopathology, 22, 491-495. doi:10.1017/S0954579410000222

Matheson, S. L., Shepherd, A. M., Pinchbeck, R. M., Laurens, K. R., \& Carr, V. J. (2013). Childhood adversity in schizophrenia: A systematic meta-analysis. Psychological Medicine, 43, 225-238. doi:10.1017/S0033291712000785

McLaughlin, K. A., Conron, K. J., Koenen, K. C., \& Gilman, S. E. (2010). Childhood adversity, adult stressful life events, and risk of past-year psychiatric disorder: A test of the stress sensitization hypothesis in a populationbased sample of adults. Psychological Medicine, 40, 1647-1658. doi:10.1017/ S0033291709992121

McLaughlin, K. A., Sheridan, M. A., \& Lambert, H. K. (2014). Childhood adversity and neural development: Deprivation and threat as distinct dimensions of early experience. Neuroscience \& Biobehavioral Reviews, 47, 578-591. doi:10.1016/j.neubiorev.2014.10.012

Miller, G. E., Chen, E., \& Zhou, E. S. (2007). If it goes up, must it come down? Chronic stress and the hypothalamic-pituitary-adrenocortical axis in humans. Psychological Bulletin, 133, 25. doi:10.1037/0033-2909.133.1.25

Miller, R., \& Plessow, F. (2013). Transformation techniques for cross-sectional and longitudinal endocrine data: Application to salivary cortisol concentrations. Psychoneuroendocrinology, 38, 941-946. doi:10.1016/j.psyneuen.2012. 09.013

Mittal, C., \& Griskevicius, V. (2014). Sense of control under uncertainty depends on people's childhood environment: A life history theory approach. Journal of Personality and Social Psychology, 107, 621-637. doi: $10.1037 / \mathrm{a} 0037398$ 
Muthen, L. K., \& Muthén, B. O. (2010). Mplus user's guide (version 6.1). Los Angeles: Author.

Myin-Germeys, I., Krabbendam, L., Delespaul, P. A. E. G., \& van Os, J. (2004) Sex differences in emotional reactivity to daily life stress in psychosis Journal of Clinical Psychiatry, 65, 805-809.

Olff, M., Langeland, W., \& Gersons, B. P. (2005). Effects of appraisal and coping on the neuroendocrine response to extreme stress. Neuroscience of Biobehavioral Reviews, 29, 457-467. doi:10.1016/j.neubiorev.2004.12.006

Palmier-Claus, J., Berry, K., Darrell-Berry, H., Emsley, R., Parker, S., Drake, R., \& Bucci, S. (2016). Childhood adversity and social functioning in psychosis: Exploring clinical and cognitive mediators. Psychiatry Research, 238, 25-32. doi:10.1016/j.psychres.2016.02.004

Paris, J. J., Franco, C., Sodano, R., Freidenberg, B., Gordis, E., Anderson, D. A., ... Frye, C. A. (2010). Sex differences in salivary cortisol in response to acute stressors among healthy participants, in recreational or pathological gamblers, and in those with posttraumatic stress disorder. Hormones and Behavior, 57, 35-45. doi:10.1016/j.yhbeh.2009.06.003

Pechtel, P., \& Pizzagalli, D. A. (2011). Effects of early life stress on cognitive and affective function: An integrated review of human literature. Psychopharmacology, 214, 55-70. doi:10.1007/s00213-010-2009-2

Pesonen, A. K., Räikkönen, K., Feldt, K., Heinonen, K., Osmond, C., Phillips, D. I., ... Kajantie, E. (2010). Childhood separation experience predicts HPA axis hormonal responses in late adulthood: A natural experiment of World War II. Psychoneuroendocrinology, 35, 758-767. doi:10.1016/ j.psyneuen.2009.10.017

Pluess, M. (2015). Individual differences in environmental sensitivity. Child Development Perspectives, 9, 138-143. doi:10.1111/cdep.12120

Pluess, M., \& Belsky, J. (2011). Prenatal programming of postnatal plasticity? Development and Psychopathology, 23, 29-38. doi:10.1017/S0954579410000623

Pluess, M., Stevens, S., \& Belsky, J. (2013). Differential susceptibility: Developmental and evolutionary mechanisms of gene-environment interactions. In M. L. Legestee, D. W. Haley, \& M. H. Bornstein (Ed.), The infant mind: Origins of the social brain (pp. 77-96). New York: Guilford Press.

Price, L. H., Kao, H. T., Burgers, D. E., Carpenter, L. L., \& Tyrka, A. R. (2013) Telomeres and early-life stress: An overview. Biological Psychiatry, 73, 1523. doi:10.1016/j.biopsych.2012.06.025

Pruessner, J. C., Wolf, O. T., Hellhammer, D. H., Buske-Kirschbaum, A., Von Auer, K., Jobst, S., ... Kirschbaum, C. (1997). Free cortisol levels after awakening: A reliable biological marker for the assessment of adrenocortical activity. Life Sciences, 61, 2539-2549. doi:10.1016/S0024-3205(97)01008-4

Read, J., van Os, J., Morrison, A. P., \& Ross, C. A. (2005). Childhood trauma, psychosis and schizophrenia: A literature review with theoretical and clinical implications. Acta Psychiatrica Scandinavica, 112, 330-350. doi:10.1111/ j.1600-0447.2005.00634.x

Repetti, R. L., Robles, T. F., \& Reynolds, B. (2011). Allostatic processes in the family. Development and Psychopathology, 23, 921-938. doi:10.1017/ S095457941100040X

Repetti, R. L., Taylor, S. E., \& Seeman, T. E. (2002). Risky families: Family social environments and the mental and physical health of offspring Psychological Bulletin, 128, 330-366. doi:10.1037/0033-2909.128.2.330

Romeo, R. D., \& McEwen, B. S. (2006). Stress and the adolescent brain. Annals of the New York Academy of Sciences, 1094, 202-214. doi:10.1196/annals.1376.022

Rössler, W., Ajdacic-Gross, V., Rodgers, S., Haker, H., \& Müller, M. (2016). Childhood trauma as a risk factor for the onset of subclinical psychotic experiences: Exploring the mediating effect of stress sensitivity in a crosssectional epidemiological community study. Schizophrenia Research, 172, 46-53. doi:10.1016/j.schres.2016.02.006

Ruby, E., Polito, S., McMahon, K., Gorovitz, M., Corcoran, C., \& Malaspina, D. (2014). Pathways associating childhood trauma to the neurobiology of schizophrenia. Frontiers in Psychological and Behavioral Science, 3, 1-17.

Rutten, B. P., Hammels, C., Geschwind, N., Menne-Lothmann, C., Pishva, E., Schruers, K., ... Wichers, M. (2013). Resilience in mental health: Linking psychological and neurobiological perspectives. Acta Psychiatrica Scandinavica, 128, 3-20. doi:10.1111/acps.12095

Schlotz, W., Kumsta, R., Layes, I., Entringer, S., Jones, A., \& Wüst, S. (2008). Covariance between psychological and endocrine responses to pharmacological challenge and psychosocial stress: A question of timing. Psychosomatic Medicine, 70, 787-796. doi:10.1097/PSY.0b013e3181810658
Seery, M. D. (2011). Challenge or threat? Cardiovascular indexes of resilience and vulnerability to potential stress in humans. Neuroscience \& Biobehavioral Reviews, 35, 1603-1610. doi:10.1016/j.neubiorev.2011.03.003

Seery, M. D., Weisbuch, M., \& Blascovich, J. (2009). Something to gain, something to lose: The cardiovascular consequences of outcome framing. International Journal of Psychophysiology, 73, 308-312. doi:10.1016/ j.ijpsycho.2009.05.006

Seiffge-Krenke, I., Aunola, K., \& Nurmi, J. E. (2009). Changes in stress perception and coping during adolescence: The role of situational and personal factors. Child Development, 80, 259-279. doi:10.1111/j.1467-8624.2008. 01258.x

Sheridan, M. A., McLaughlin, K. A., Winter, W., Fox, N., Zeanah, C., \& Nelson, C. A. (2018). Early deprivation disruption of associative learning is a developmental pathway to depression and social problems. Nature Communications, 9, 2216. doi:10.1038/s41467-018-04381-8

Sladek, M. R., Doane, L. D., Luecken, L. J., \& Eisenberg, N. (2016). Perceived stress, coping, and cortisol reactivity in daily life: A study of adolescents during the first year of college. Biological Psychology, 117, 8-15. doi:10.1016/j.biopsycho.2016.02.003

Slattery, M. J., Grieve, A. J., Ames, M. E., Armstrong, J. M., \& Essex, M. J. (2013). Neurocognitive function and state cognitive stress appraisal predict cortisol reactivity to an acute psychosocial stressor in adolescents. Psychoneuroendocrinology, 38, 1318-1327. doi:10.1016/j.psyneuen.2012.11.017

Spear, L. P. (2009). Heightened stress responsivity and emotional reactivity during pubertal maturation: Implications for psychopathology. Development and Psychopathology, 21, 87-97.

Stevens, J. S., \& Hamann, S. (2012). Sex differences in brain activation to emotional stimuli: A meta-analysis of neuroimaging studies. Neuropsychologia, 50, 1578-1593. doi:10.1016/j.neuropsychologia.2012.03.011

Stroud, L. R., Salovey, P., \& Epel, E. S. (2002). Sex differences in stress responses: Social rejection versus achievement stress. Biological Psychiatry, 52, 318-327. doi:10.1016/S0006-3223(02)01333-1

Suzuki, A., Poon, L., Papadopoulos, A. S., Kumari, V., \& Cleare, A. J. (2014). Long term effects of childhood trauma on cortisol stress reactivity in adulthood and relationship to the occurrence of depression. Psychoneuroendocrinology, 50, 289-299. doi:10.1016/j.psyneuen.2014.09.007

Tarullo, A. R., \& Gunnar, M. R. (2006). Child maltreatment and the developing HPA axis. Hormones and Behavior, 50, 632-639. doi:10.1016/ j.yhbeh.2006.06.010

Tolin, D. F., \& Foa, E. B. (2006). Sex differences in trauma and posttraumatic stress disorder: A quantitative review of 25 years of research. Psychological Bulletin, 132, 959. doi:10.1037/0033-2909.132.6.959

Trotman, H. D., Holtzman, C. W., Walker, E. F., Addington, J. M., Bearden, C. E., Cadenhead, K. S., ... Tsuang, M. T. (2014). Stress exposure and sensitivity in the clinical high-risk syndrome: Initial findings from the North American Prodrome Longitudinal Study (NAPLS). Schizophrenia Research, 160, 104-109. doi:10.1016/j.schres.2014.09.017

Turner, M. J., Jones, M. V., Sheffield, D., Barker, J. B., \& Coffee, P. (2014). Manipulating cardiovascular indices of challenge and threat using resource appraisals. International Journal of Psychophysiology, 94, 9-18. doi:10.1016/ j.ijpsycho.2014.07.004

Tyrka, A. R., Price, L. H., Gelernter, J., Schepker, C., Anderson, G. M., \& Carpenter, L. L. (2009). Interaction of childhood maltreatment with the corticotropin-releasing hormone receptor gene: Effects on hypothalamic-pituitary-adrenal axis reactivity. Biological Psychiatry, 66, 681-685. doi:10.1016/ j.biopsych.2009.05.012

Tyrka, A. R., Wier, L., Price, L. H., Ross, N., Anderson, G. M., Wilkinson, C. W., \& Carpenter, L. L. (2008). Childhood parental loss and adult hypothalamic-pituitary-adrenal function. Biological Psychiatry, 63, 11471154. doi:10.1016/j.biopsych.2008.01.011

Ullman, S. E., \& Peter-Hagene, L. (2014). Social reactions to sexual assault disclosure, coping, perceived control, and PTSD symptoms in sexual assault victims. Journal of Community Psychology, 42, 495-508. doi:10.1002/ jcop. 21624

van Harmelen, A. L., van Tol, M. J., van der Wee, N. J., Veltman, D. J., Aleman, A., Spinhoven, P., ... Elzinga, B. M. (2010). Reduced medial prefrontal cortex volume in adults reporting childhood emotional maltreatment. Biological Psychiatry, 68, 832-838. doi:10.1016/j.biopsych.2010.06.011 
van Nierop, M., Lecei, A., Myin-Germeys, I., Collip, D., Viechtbauer, W., Jacobs, N., ... van Winkel, R. (2018). Stress reactivity links childhood trauma exposure to an admixture of depressive, anxiety, and psychosis symptoms. Psychiatry Research, 260, 451-457. doi:10.1016/j.psychres. 2017.12.012

Wadsworth, M. E. (2015). Development of maladaptive coping: A functional adaptation to chronic, uncontrollable stress. Child Development Perspectives, 9, 96-100. doi:10.1111/cdep.12112

Walker, E. F., Sabuwalla, Z., \& Huot, R. (2004). Pubertal neuromaturation, stress sensitivity, and psychopathology. Development and Psychopathology, 16, 807-824. doi:10.1017/S0954579409000066

Walker, E. F., Trotman, H. D., Pearce, B. D., Addington, J., Cadenhead, K. S., Cornblatt, B. A., ... Tsuang, M. T. (2013). Cortisol levels and risk for psychosis: Initial findings from the North American prodrome longitudinal study. Biological Psychiatry, 74, 410-417. doi:10.1016/j.biopsych. 2013.02.016

Wichers, M. C., Barge-Schaapveld, D. Q. C. M., Nicolson, N. A., Peeters, F., De Vries, M., Mengelers, R., \& van Os, J. (2009). Reduced stress-sensitivity or increased reward experience: The psychological mechanism of response to antidepressant medication. Neuropsychopharmacology, 34, 923. doi:10.1038/ npp.2008.66

Wirtz, P. H., von Känel, R., Emini, L., Suter, T., Fontana, A., \& Ehlert, U. (2007). Variations in anticipatory cognitive stress appraisal and differential proinflammatory cytokine expression in response to acute stress. Brain, Behavior, and Immunity, 21, 851-859. doi:10.1016/j.bbi.2007.02.003

Wüst, S., Federenko, I., Hellhammer, D. H., \& Kirschbaum, C. (2000). Genetic factors, perceived chronic stress, and the free cortisol response to awakening. Psychoneuroendocrinology, 25, 707-720. doi:10.1016/S0306-4530(00) 00021-4

Young, E. A., \& Breslau, N. (2004). Saliva cortisol in posttraumatic stress disorder: A community epidemiologic study. Biological Psychiatry, 56, 205209. doi:10.1016/j.biopsych.2004.05.01

Zimmer-Gembeck, M. J., \& Skinner, E. A. (2011). The development of coping across childhood and adolescence: An integrative review and critique of research. International Journal of Behavioral Development, 35, 1-17. doi:10.1177/0165025410384923 